\title{
Investigating the Strongyle Populations, with Emphasis on Strongylus vulgaris (Nematoda: Strongylidae) in Romanian Horses, Based on Larval Cultures
}

\author{
Marius Catalin BUZATU, Ioan Liviu MITREA, Alexandra GRUIANU, Mariana IONITA* \\ Department of Parasitology and Parasitic \& Animal Biology, Faculty of Veterinary Medicine, University of \\ Agronomic Sciences and Veterinary Medicine of Bucharest, Spl. Independentei 105, Bucharest, Romania \\ *corresponding author: ionitamary@yahoo.com
}

Bulletin UASVM Veterinary Medicine 74(2)/2017

Print ISSN 1843-5270; Electronic ISSN 1843-5378

doi:10.15835/buasvmcn-vm:0026

\begin{abstract}
This study aimed to investigate the presence of Strongylus vulgaris on different horse establishments in Romania. A total number of 380 horses were enrolled in the study, representing: three stud farms ( $n=156)$; four sport/recreational establishments $(n=75)$; and working horses $(n=149)$. Overall, 106 premises/yards from 17 localities in 9 counties from North-Eastern, Center and Southern Romania were visited. Fresh fecal sample were collected from individual horses and were analyzed by a modified McMaster method for fecal strongyle egg per gram counting. Further, larval cultures were performed for morphological identification of $S$. vulgaris third stage larvae. Overall, of the investigated horses from studs, sport/recreational units, and working horses, $84.60 \%$, $44.0 \%$, and $79.20 \%$, respectively were positive for strongyle. On coprocultures, cyathostomin-larvae were the most prevalent in all horse-establishment types, while $S$. vulgaris larvae were found only in working horses $112.1 \%$; $\mathrm{n}=18$ ). Other strongylin species have been identified, namely S. equinus, S. edentatus, Oesophagodontus robustus, and Triodontophorus spp. all in working horses, and Craterostomum acuticaudatum, in both working horses and horses for sport units. However, further studies are planned by using more sensitive technique for monitoring of $S$. vulgaris in Romanian horse farms.
\end{abstract}

Keywords: horses, larval cultures, Romania, Strongylus vulgaris

\section{INTRODUCTION}

The large strongyle Strongylus vulgaris (Nematoda: Strongylinae) is the most pathogenic strongyle species and the most important parasite in horses (Lyons et al., 2011; Mitrea, 2011). Adult worms live in the cecum and right ventral colon, while its migrating fourth (L4) and fifth (L5) stage larvae are responsible for severe verminous endarteritis, tromboembolism and infarction of the cranial mesenteric artery and its branches characterized by painful colic syndrome, which can be fatal (Duncan and Pirie, 1975; Lyons et al., 2011; Mitrea, 2011). Despite of the fact that the intensive anthelmintic treatment strategies designed to control $S$. vulgaris have been successful in reducing its prevalence, morbidiy and mortality due to this parasite (Kaplan, 2002), surveys of horse populations across the world still document its occurrence (Nielsen, 2012). Therefore, S. vulgaris still represents a potential threat to equine health and it is a need to monitor horse farms for its presence. In this context, field studyes to investigate the occurence and prevalence of different equine strongyle species in horse populations from different geografical areas and under different breeding systems are very important to develop sustainable control programs.

However, for living animals, the microscopic examination of fecal strongyle eggs does not allow species specific differentiation of mixed natural strongyle infections, due to the egg morphology 
similarities (Lichtenfels et al., 2008). Therefore, alternative methods have been developed, such as larval cultures. Larval culturing is the most practical method to differentiate and identify different equine strongyle species or genera (up to 17), based on the morphological characteristics of the third larval stage (L3) (Cernea et al., 2008; Andersen et al., 2013).

By this study was aimed to investigate the presence of $S$. vulgaris on different horse establishments in Romania, based on larval cultivation.

\section{MATERIALS AND METHODS}

Animals

A total number of 380 horses were enrolled in the study, representing: three horse farms $(n=156) ;$ four recreational/sport establishments $(n=75)$; and working horses $(\mathrm{n}=148)$ aging from 1.2 to 28 years. Overall, 106 yards from 17 localities in 9 counties from North-Eastern, Center and Southern Romania were visited (Tab. 1).

Fecal analyses, Larval culturing, and identification of the third larval stage

Fresh fecal samples were collected from individual horses and were firstly analyzed by a modified McMaster method for fecal strongyle egg per gram (EPG) counting. Further, individual larval cultures were performed on positive samples, for the morphological identification of $S$. vulgaris larvae (third stage L3), as described before (Anutescu et al., 2016). Briefly, for individual larval cultures (LC), 10 grams of faeces were suspended in humidity chambers which were incubated for 14 days at $22-24^{\circ} \mathrm{C}$ : LC were daily ventilated and moistened if neccessary. After culturing, L3 were harvested after $24 \mathrm{~h}$ sedimentation, using a modified Baermann method (Bellaw and Nielsen, 2015). For each larval culture, $1 \mathrm{ml}$ of sediment was collected, centrifuged at $3000 \mathrm{rpm}$ for 5 minutes, and analyzed according to the protocol described by Schneider et al. (2014), as follows: $100 \mu \mathrm{l}$ aliquot was used for counting and morphological identification and differentiation of larvae (larvae were immobilized with Lugol's iodine); the remaining sediment $(900 \mu \mathrm{l})$ was analyzed for identification of $S$. vulgaris larvae. The strongyle larvae were identified using morphological keys, based on: number, shape, and arrangement of the intestinal cells, type of esophagus, tail length (Cernea et al., 2008; Kornas et al., 2009).

\section{RESULTS AND DISCUSSIONS}

Overall, of the investigated horses from stud farms, sport/recreational units, and working horses, $84.60 \%$, $44.0 \%$, and $79.20 \%$, respectively were positive for strongyle eggs (Tab. 1), with the individual of EPG counts varying from 0 to 6675 , 5250 , and 3700 , respectively.

For morphological identification of $S$. vulgaris larvae, a total of 283 individual larval cultures were performed. The presence and frequency of diffent cyathostomin and strongylin L3 morphotypes / species was established based on the examination of larvae in $1 \mathrm{ml}$ of sediment / each individual cultures and the prevalence based on the identified L3 from an aliquote of $100 \mu \mathrm{l} /$ each LC.

The morphological identification of L3 was made based on the following criteria: type of esophagus, intestinal cells (number, shape, and arrangement), and length of tail (Kornas et al., 2009). Accordingly, there has been described different types of arrangements: of 8 intestinal cells encountered in cyathostomins, called A-D, as well as other morphotypes, namely type $\mathrm{E}$ ( 6 cells), type $\mathrm{F}$ (7 cells) and type G (8 nonspecific cells), $\mathrm{H}$ ( 9 cells), Gyalocephalus capitatus (12 cells), and Poteriostomum spp. (16 cells). Similar morphological keys are also described for the large strongyle species, which have higer number of intestinal cells (16 - 32) (Madeira de Carvalho et al. ,2008; Cernea et al., 2008).

S. vulgaris larvae (Fig. 1) were identified based on the following characteristics: long dimension (900 - $1110 \mu \mathrm{m}$ ), short esophagus, long tail, and 28 - 32 distinct intestinal cells (Cernea et al., 2008).

Overall, on coprocultures, larval differentiation and identification showed mixed strongyle infections, with small strongyle species (cyathostomins) the most prevalent in all horses investigated, represented by cyathostomin morphotype A, C, D as the most frequent, being identified in the majority of horses from all breeding systems, followed by the morphotype B, E, F, G, H, Gyalocephalus capitatus, and Poteriostomum spp., which were identified with a lower frequency (Tab. 2).

S. vulgaris larvae were found only in working horses $(n=18 ; 12.1 \%)$; the positive animals aged between 2 and 20 years. Other strongylinae were identified, as follows: Strongylus equinus, S. edentatus, Oesophagodontus robustus, and Triodontophorus spp. all in working horses, and Craterostomum acuticaudatum, in both working horses and horses for sport (Tab. 2). 
Tab 1. Prevalence of strongyle-egg-type infection and Strongylus vulgaris (L3) in horses, stratified by their geographical originating area and horse breeding systems, Romania

\begin{tabular}{|c|c|c|c|c|c|c|}
\hline \multicolumn{2}{|c|}{$\begin{array}{c}\text { Breading system/ } \\
\text { origin area }\end{array}$} & \multicolumn{2}{|c|}{ Premises/yards } & \multicolumn{3}{|c|}{ Horses: number; percentage (\%) } \\
\hline region & County* & $\begin{array}{l}\text { Premises } \\
\text { (L) }\end{array}$ & $\begin{array}{c}\text { yards } \\
\text { (number) }\end{array}$ & investigated & $\begin{array}{l}\text { positive for } \\
\text { strongyle } \\
\text { egg }\end{array}$ & $\begin{array}{l}\text { positive for } \\
\text { Strongylus } \\
\text { vulgaris L3 }\end{array}$ \\
\hline \multicolumn{7}{|c|}{ Working horses $(n=148)$} \\
\hline \multirow{4}{*}{ North-Eastern } & \multirow{2}{*}{ SV } & L.1 & 8 & 10 & $8(80.0)$ & $1(10.0)$ \\
\hline & & L. 2 & 10 & 11 & $5(45.4)$ & 0 \\
\hline & \multirow{2}{*}{ BT } & L.3 & 8 & 17 & $11(64.7)$ & $2(11.7)$ \\
\hline & & L.4 & 6 & 13 & $8(61.5)$ & $4(30.7)$ \\
\hline \multirow{2}{*}{ Center } & \multirow{2}{*}{ BV } & L.5 & 19 & 32 & $25(78.1)$ & 0 \\
\hline & & L. 6 & 28 & 33 & $31(93.9)$ & $7(21.2)$ \\
\hline \multirow{5}{*}{$\begin{array}{c}\text { South/ } \\
\text { South-Eastern }\end{array}$} & $\mathrm{BZ}$ & L.7 & 6 & 12 & $12(100)$ & $1(8,3)$ \\
\hline & IL & L.8 & 5 & 6 & $3(50)$ & $2(33.3)$ \\
\hline & IF & L.9 & 1 & 5 & $5(100)$ & 0 \\
\hline & $\mathrm{TL}$ & L.10 & 8 & 10 & $10(100)$ & $1(10.0 \%)$ \\
\hline & $\begin{array}{l}\text { Total } \\
(\%)\end{array}$ & 10 & 99 & 149 & $\begin{array}{c}118 \\
(79.2)\end{array}$ & $\begin{array}{c}18 \\
(12.1)\end{array}$ \\
\hline \multicolumn{7}{|c|}{ Sport/recreational horse establishments $(n=75)$} \\
\hline \multirow{4}{*}{$\begin{array}{c}\text { South/ } \\
\text { South-Eastern }\end{array}$} & TL & L11 & 1 & 10 & $\begin{array}{c}7 \\
(70.0)\end{array}$ & 0 \\
\hline & PH & L.12 & 1 & 12 & $\begin{array}{c}11 \\
(91.66)\end{array}$ & 0 \\
\hline & IF & L.13 & 2 & 53 & $\begin{array}{c}15 \\
(28.30)\end{array}$ & 0 \\
\hline & $\begin{array}{l}\text { Total } \\
(\%)\end{array}$ & 3 & 4 & 75 & $\begin{array}{c}33 \\
(44.0)\end{array}$ & 0 \\
\hline \multicolumn{7}{|c|}{ Stud farms $(n=156)$} \\
\hline Center & BV & L.14 & 1 & 40 & $\begin{array}{c}34 \\
(85.0)\end{array}$ & 0 \\
\hline \multirow{3}{*}{ South-Eastern } & $\mathrm{BZ}$ & L.15 & 1 & 56 & $\begin{array}{c}49 \\
(87.5)\end{array}$ & 0 \\
\hline & CT & L.16 & 1 & 60 & $\begin{array}{c}49 \\
(81.66)\end{array}$ & 0 \\
\hline & $\begin{array}{l}\text { Total } \\
(\%)\end{array}$ & 3 & 3 & 156 & $\begin{array}{c}132 \\
(84.60)\end{array}$ & 0 \\
\hline \multicolumn{2}{|c|}{ TOTAL } & 16 & 106 & 380 & & \\
\hline
\end{tabular}

Legend:*BZ-Buzau; BV-Brasov; BT-Botosani; CT-Constanta; IF-Ilfov; PH-Prahova; SV: Suceava: TL-Tulcea 
Tab. 2. Structure of strongyle populations, based on larval cultures, in horses from different Romanian breeding systems

\begin{tabular}{|c|c|c|c|c|c|c|c|c|c|c|c|c|c|c|c|c|}
\hline \multirow{2}{*}{$\begin{array}{l}\text { Horses' } \\
\text { Category }\end{array}$} & \multicolumn{16}{|c|}{ Number of horses positive for different cyatostominae ${ }^{c}$ and strongyline ${ }^{s}$ third stage larvae (L3) } \\
\hline & $A^{c}$ & $\mathrm{~B}^{c}$ & $\mathrm{C}^{\mathrm{c}}$ & $\mathrm{D}^{c}$ & $\mathrm{E}^{\mathrm{c}}$ & $\mathrm{F}^{\mathrm{c}}$ & $\mathrm{G}^{\mathrm{c}}$ & $\mathrm{H}^{\mathrm{c}}$ & $G y^{c}$ & $P O^{c}$ & $S v^{\infty}$ & $\mathrm{Sed}^{k}$ & $\operatorname{Seq}$ & $O e^{s}$ & $C r^{s}$ & $\operatorname{Tr}^{6}$ \\
\hline $\begin{array}{l}\text { Working } \\
\text { horses } \\
(\mathrm{n}=118)\end{array}$ & 118 & 0 & 88 & 35 & 0 & 0 & 0 & 4 & 11 & 3 & 18 & 1 & 2 & 4 & 5 & 1 \\
\hline $\begin{array}{l}\text { Sport } \\
\text { horses } \\
(\mathrm{n}=33)\end{array}$ & 33 & 0 & 31 & 9 & 0 & 2 & 2 & 0 & 0 & 0 & 0 & 0 & 0 & 4 & 0 & 0 \\
\hline $\begin{array}{l}\text { Stud farms } \\
(\mathrm{n}=132)\end{array}$ & 132 & 7 & 101 & 68 & 9 & 26 & 10 & 4 & 3 & 2 & 0 & 0 & 0 & 0 & 0 & 0 \\
\hline
\end{tabular}

Note: C: Cyathsotominae: A - H: cyathostomins morphotype A to H; Gy: Gyalocephalus capitatus; Po: Poteriostomum spp.; 's: Strongylinae: S.v: Strongylus vulgaris; S.ed: Strongylus edentatus; S. eq: Strongylus equinus: Oe: Oesophagodontus robustus: Cr: Craterostomum acuticaudatum; Tr: Triodontophorus spp.

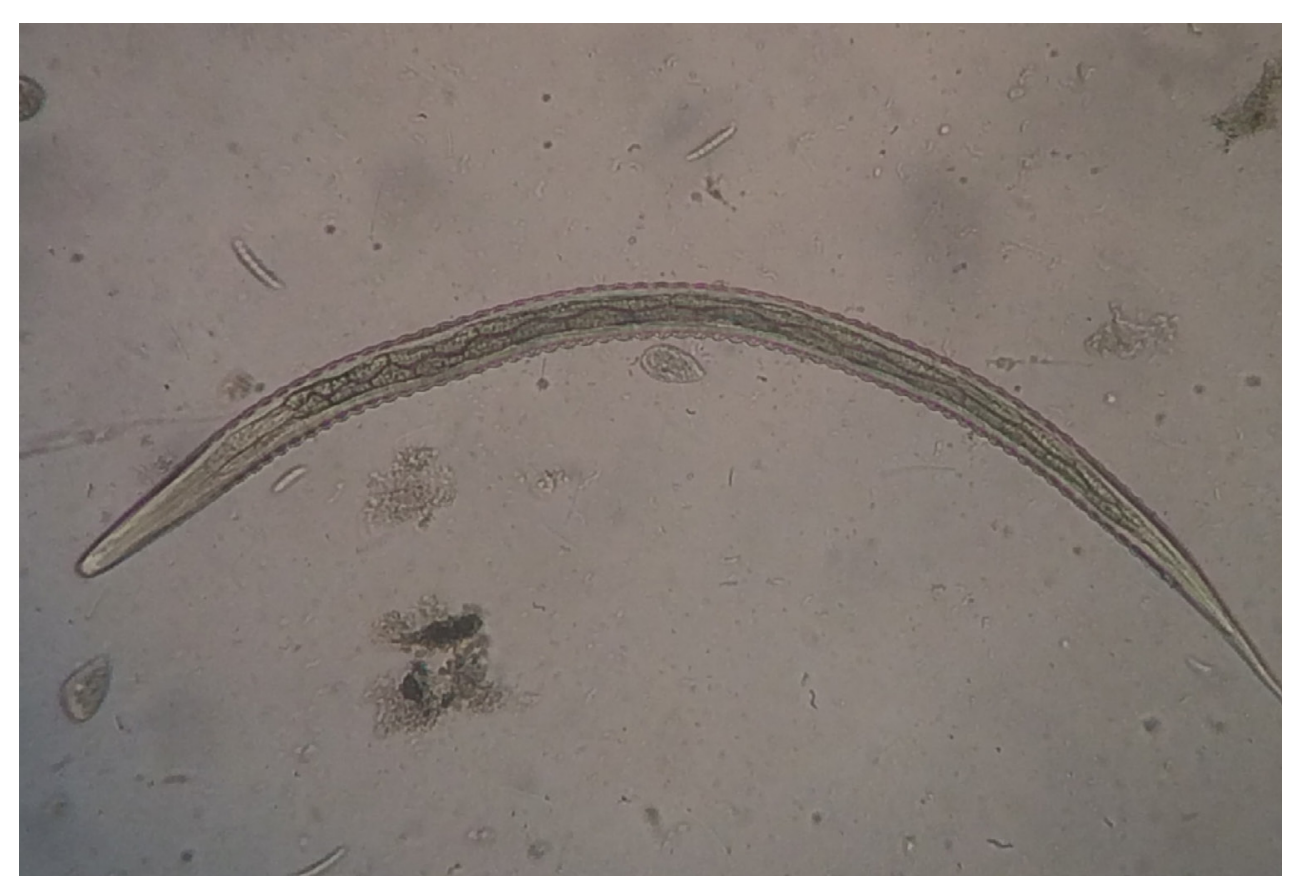

Fig. 1. Third stage of Strongylus vulgaris (recovered from larval cultures (100x)

Subsequently of examination of an aliquote of $100 \mu \mathrm{l}$ in each larval culture (LC) a total number of 10430 (from 118 LC), 3630 (from 33 LC), and 13740 (from 149 LC) larvae were counted on working horses, horses from sport units, and stud farms, respectively. The cytahostomin morphotype A was the most prevalent (varying from 65.8 to $70.2 \%$ ), followed by the morphotype C (prevalence between 9.4 and 18.7\%), and D (2.8 - 6.\%). Other small strongyle species were also identified, but in lower prevalence. Of the large strongyles, S. vulgaris, S. edentatus, Triodonthophorus spp. larvae were identified all LC from working horses $(0.4 \%)$, while Craterostomum acuticaudatum was found in those from the both working $(0.4 \%)$ and sport horses (1.1\%) (Tab. 3). 
Tab. 3. Prevalence of cyathostomin and strongylin third larvae morphotypes (\% of L3 identified in 100 $\mu \mathrm{l})$ in horses, stratified by different breeding systems

\begin{tabular}{|c|c|c|c|c|c|c|c|c|c|c|c|c|c|c|c|c|c|}
\hline \multirow{2}{*}{$\begin{array}{c}\text { Horses' } \\
\text { category } \\
\text { / L3 } \\
\text { identified }\end{array}$} & \multicolumn{17}{|c|}{$\begin{array}{l}\text { L3 morphotypes / species of cyatostominae }{ }^{c} \text { and strongylinae } \\
\text { (identified in the aliquot of } 100 \mu \text { l of each LC) }\end{array}$} \\
\hline & $\mathrm{A}^{\mathrm{c}}$ & $\mathrm{B}^{\mathrm{c}}$ & $\mathrm{C}^{\mathrm{c}}$ & $\mathrm{D}^{\mathrm{c}}$ & $\mathrm{E}^{\mathrm{c}}$ & $\mathrm{F}^{\mathrm{c}}$ & $\mathrm{G}^{\mathrm{c}}$ & $\mathbf{H}^{\mathrm{c}}$ & $G y^{c}$ & $P o^{c}$ & $\mathbf{N}$ & $S v^{s}$ & $\operatorname{Sed}^{s}$ & $S e q^{s}$ & $O e^{s}$ & $\mathrm{Cr}^{s}$ & $T r^{s}$ \\
\hline \multicolumn{18}{|c|}{ Working horses } \\
\hline $\begin{array}{c}\text { L3 } \\
(n=10430)\end{array}$ & 65.8 & 0 & 16.9 & 2.8 & 0 & 0 & 0 & 0 & 0 & 0.4 & 12.7 & 0.4 & 0.4 & 0 & 0 & 0.4 & 0.4 \\
\hline \multicolumn{18}{|c|}{ Sport horses } \\
\hline $\begin{array}{c}\mathrm{L3} \\
(\mathrm{n}=3630)\end{array}$ & 70.2 & 0 & 18.7 & 3.0 & 0 & 0.6 & 0 & 0 & 0 & 0 & 6.3 & 0 & 0 & 0 & 0 & 1.1 & 0 \\
\hline \multicolumn{18}{|c|}{ Stud farms } \\
\hline $\begin{array}{c}\mathrm{L3} \\
(\mathrm{n}=13740)\end{array}$ & 67.1 & 0.7 & 9.4 & 6.8 & 0.5 & 3.1 & 0.3 & 0.3 & 0.3 & 0.15 & 11.6 & 0 & 0 & 0 & 0 & 0 & 0 \\
\hline
\end{tabular}

Note: C: Cyathsotominae: A-H: cyathostomins morphotype A to H; Gy: Gyalocephalus capitatus; Po: Poteriostomum spp.; 's: Strongylinae: S.v: Strongylus vulgaris; S.ed: Strongylus edentatus; S.eq: Strongylus equinus: Oe: Oesophagodontus robustus: Cr: Craterostomum acuticaudatum; Tr: Triodontophorus spp.

Overall, this study emphasizes that strongyle infections are highly prevalent in all horse breeding systems. These findings are in line with previously reported data of epidemiological studies performed in different areas of Romania (Covasa and Miron, 2011; Morariu et al., 2012; Buzatu et al., 2013, 2014, 2016, Ionita et al., 2013, Cernea et al., 2008, 2015). However, data about prevalence of different strongyle species in Romanian horses, and particular about the most pathogenic large strongyle $S$. vulgaris are still scarce. Through larval culturing, this study revealed mixed strongyle populations, comprising a complex of cytostomin species, with the morphotype A as predominat, but also strongylin species, including $S$. vulgaris, $S$. edentatus, and $S$. equinus in working horses. These results are consistent also with previous studies carried out in Romania reporting a prevalence of $10.3 \%$ for S. vulgaris (Cernea et al., 2015). Different surveys showed that the $S$. vulgaris species is more commonly found in working horses, as it was in the present study, or in horses from farms where anthelmintic treatments are iregularly administered or with a lower intensity (Kyvsgaard et al., 2011). Therefore, due to the intensive anthelmintic treatment regime in the last decades, S. vulgaris is reported now in lower prevalence in well managed farms (Kaplan, 2002) as it is in Switzerland, Germany (Kaspar et al., 2017). In Poland, in slaughtered horses was of $S$. vulgaris was the most dominant nematode (22.8\%), followed by $S$. edentatus $(18.3 \%)$ and $S$. equinus (1.7\% ) (Studzińska et al., 2012).

The knowledge on the biodiversity of larval morphotypes within different strongyle populations might be an useful tool for indirect asessment of the susceptibility or chemoresisance of the cyathostomins populations. These findings are of relevance, as the morphotype A is reported as being produced by the most prevalent and resistant cyathostomins (Madeira de Carvalho et al., 2008).

Nonetheless, $S$. vulgaris has become a rare parasite in well managed horse farms during the past 50 years (Kaplan, 2002) due to the frequent prophylactic anthelmintic treatments. Other studies, show occurrence of $S$. vulgaris, with low prevalence (Scheinder et al., 2014), but it might be also depending on the method used for monitoring. However, currently, the are reports showing that stud farms using selective therapy, based on less frequency of anthelmintic treatments, might be at risk for re-emerging of $S$. vulgaris as reported in Denmark (Nielsen et al., 
2012). Therefore, this parasite is still a threat for the horse health and need to be monitorized; larval cultures near by other more sensitive methods based on PCR are useful tools and standard method in some European countries (Nielsen et al., 2012; Kaspar et al., 2017). Recently, Kaspar et al. (2017) demonstrated that real-time PCR is more sensitive and detected a significantly higher proportion of positives of $S$. vulgaris than larval culture. Therefore, further studies are planned by using more sensitive technique PCR-based for monitoring of $S$. vulgaris in Romanian horse farms.

\section{CONCLUSION}

In this study we report the occurrence of $S$. vulgaris in working horse populations. This study represents the base for further investigations, including by using more sensitive tools, to monitor for $S$. vulgaris on Romanian horse farms.

Acknowledgments: This work was supported by UEFISCDI-Romania, project PN-II-RUTE-2014-4-1432.

\section{REFERENCES}

1. Andersen UV, Howe DK, Olsen SN, Nielsen MK (2013). Recent advances in diagnosing pathogenic equine gastrointestinal helminths: The challenge of prepatent detection. Veterinary Parasitology, 192: 1-9.

2. Anuțescu SM, Buzatu MC, Gruianu A, Bellaw J, Mitrea IL, Ioniță M (2016), Use of larval cultures to investigate the structure of strongyle populations in working horses, Romania: preliminary data. AgroLife Scientific Journal, 5: 9-14.

3. Bellaw LJ, Nielsen KM (2015). Evaluation of Baermann apparatus sedimentation time on recovery of Strongylus vulgaris and S. edentatus third stage larvae from equine coprocultures. Veterinary Parasitology, 211: $99-101$.

4. Buzatu MC, Ioniță M, Mitrea IL (2013). Coprological prevalence of intestinal parasites and strongyle epg profiles of working horses from north-eastern and South-Eastern Romania. Scientific Works, Seria C, Veterinary Medicine, 59: 62-67.

5. Buzatu MC, Mitrea IL, Miron L, Ioniță M (2014). Coprological investigations on strongyle EPG profiles in working horses and horses residing in stud farms in Romania. Journal of Biotechnology, 185: S42.

6. Buzatu MC, Mitrea IL, Lyons ET, Ionita M (2016). Epidemiological study on parasite infections in horses from different types of equine establishemnts, Romanai. AgroLife Scientific Journal, 5: 31-35.
7. Cernea M, Madeira de Carvalho LM, Cozma V (2008). Atlas de diagnostic al strongilidozelor la ecvine. Academic Press, Cluj-Napoca.

8. Cernea M, Cristina RT, Ștefănuț LC, Madeira de Carvalho LM, Taulescu MA, Cozma V (2015). Screening for antihelmintic resistance in equid strongyles (Nematoda) in Romania. Folia Parasitologica (Praha), 62: 023.

9. Covașă CT, Miron LD (2011). Prevalence study of digestive and the serous cavities endoparasitosis in horses from Iassy city area. Lucr. St. USAMV Iasi, Seria Medicina Veterinara, 54: 302-306.

10. Duncan JL, Pirie HM (1975). The pathogenesis of single experimental infections with Strongylus vulgaris in foals. Research in Veterinary Science, 18: 82-93.

11. Ioniță M, Buzatu MC, Enachescu V, Mitrea IL (2013). Coprological prevalence and intensity of gastrointestinal parasites in horses in some Romanian studs: preliminary data. AgroLife Scientific Journal, 2: 207-212.

12. Kaplan RM (2002) Anthelmintic resistance in nematodes of horses. Veterinary Research, 33:491-507.

13. Kaspar A, Pfister K, Nielsen MK, Silaghi C, Fink H, Scheuerle MC (2017). Detection of Strongylus vulgaris in equine faecal samples by Real-time PCR and larval culture - method comparison and occurrence assessment. BMC Veterinary Research, 13:19, DOI 10.1186/s12917-016-0918-y.

14. Kornas S, Jakub Gawor J, Cabaret J, Molenda K, Skalska M, Nowosad B (2009). Morphometric identification of equid cyathostome (Nematoda: Cyathostominae) infective larvae. Veterinary Parasitology, 162: 290-294.

15. Kyvsgaard NC, Lindbom J, Andreasen LL, LunaOlivares LA, Nielsen MK, Monrad J (2011). Prevalence of strongyles and efficacy of fenbendazole and ivermectin in working horses in El Sauce, Nicaragua. Veterinary Parasitology, 181:248-254.

16. Lichtenfels JR, Kharchenko VA, Dvojnos GM (2008). Illustrated identification keys to strongylid parasites (strongylidae: Nematoda) of horses, zebras and asses (Equidae). Veterinary Parasitology, 156: 4-161.

17. Lyons ET, Ionita M, Tolliver SC (2011). Important gastrointestinale parasites (pp. 292-301), in Equine reproduction. Ed. Wiley-Blackwell, West Sussex.

18. Madeira de Carvalho LM, Cernea MS, Martins S, Sousa S, Gersão S, Cernea LO (2008). Comparative study of cyathostomin horse infection in Portugal and Romania based in L3 subpopulations of Cyathostomum sensu latum. Scientia Parasitologica, 2: 48-56.

19. Mitrea IL (2011). Parazitologie si Boli parazitare. Editura Ceres, București.

20. Morariu S, Oprescu I, Mederle N, Ilie M, Dărăbuș G (2012). Helminth Parasites in horses from five locations of Arad County. Scientific Papers: Animal Science and Biotehnologies, 45: 184-187. 
21. Nielsen MK (2012). Sustainable equine parasite control: Perspective and research needs. Veterinary Parasitology, 185: 32-44.

22. Nielsen MK, Vidyashankar AN, Olsen SN, Monrad J, Thamsborg SM. (2012), Real-time PCR evaluation of Strongylus vulgaris in horses on farms in Denmark and Central Kentucky. Veterinary Parasitology, 189: 260266.
23. Schneider S, Pfister K, Becher MA, Scheuerle CM (2014). Strongyle infections and parasitic control strategies in German horses-a risk assessment. BMC Veterinary Research, 10: 262-271.

24. Studzińska MB, Tomczuk K, Demkowska-Kutrzepa M, Szczepaniak K. (2012), The Strongylidae belonging to Strongylus genus in horses from southeastern Poland. Parasitol Res. 111(4):1417-21. 